\title{
Association of Admission Blood Glucose Level with All-Cause Mortality According to Age in Patients with Community Acquired Pneumonia
}

\author{
Yejing Shen ${ }^{1,2}$ \\ Xiaowen $\mathrm{Xu}^{2}$ \\ Siming Meng ${ }^{2}$ \\ Meng Qin ${ }^{2}$ \\ Hailing $\mathrm{Li}^{2}$ \\ Dejie Chu' \\ Cuixia Zheng ${ }^{2}$
}

'Department of Respiratory Medicine, Shanghai Eighth People's Hospital, Shanghai, 200235, People's Republic of China; ${ }^{2}$ Department of Respiratory Medicine, Yangpu Hospital Affiliated to Tongji University, Shanghai, 200090, People's Republic of China
Correspondence: Dejie Chu

Department of Respiratory Medicine, Shanghai Eighth People's Hospital, 8 Caobao Road, Shanghai, 200235, People's Republic of China

Email chudejie@yandex.com

\section{Cuixia Zheng}

Department of Respiratory Medicine, Yangpu Hospital Affiliated to Tongji University, 450 Tengyue Road, Shanghai, 200090, People's Republic of China Email zhengcuixiash@I63.com
Objective: To assess the impact of blood glucose levels on the prognosis of patients with community-acquired pneumonia (CAP) who were elderly or middle-aged.

Methods: From January 1, 2018, to December 31, 2020, patients with CAP ( $\geq 45$ years) were retrospectively enrolled in this observational study. They were stratified by age (45-64 or $\geq 65$ years) and blood glucose level $(\geq 11.1$ or $<11.1 \mathrm{mmol} / \mathrm{l})$. The effect of admission blood glucose on 28-day mortality was assessed with the Cox proportional hazards model, adjusted for demographic factors and comorbidity.

Results: Among 1656 patients with CAP, increased blood glucose (HR=2.08, 95\% CI: 1.38 $3.49 ; P<0.01)$ and advanced age $(\mathrm{HR}=2.76,95 \% \mathrm{CI}: 1.65-3.77 ; P<0.01)$ were significantly associated with a higher risk of 28-day mortality, after controlling for potential confounding factors. The strength of the association of blood glucose level with 28-day mortality decreased with age $(P=0.01$ for the interaction) as the adjusted HRs for death were 4.48 (95\% CI: $1.40-13.65 ; P<0.01)$ for middle-age patients $45-64$ years and 1.52 (95\% CI: 1.09 $2.17 ; P=0.05$ ) for elderly patients $\geq 65$ years.

Conclusion: The association of blood glucose level upon admission for CAP with all-cause mortality was stronger at younger ages.

Keywords: age, community-acquired pneumonia, hyperglycemia, mortality, prognosis

\section{Introduction}

Community-acquired pneumonia (CAP) is a common respiratory disease that causes significant morbidity and mortality throughout the world. ${ }^{1,2}$ The incidence rate of CAP for the overall population is $7.13 / 1000$ person-years in China, which appears to increase in an age-dependent manner from 2.40/1000 person-years for younger individuals (18-30 years) to $14.98 / 1000$ person-years for oldest-old subjects ( $\geq 80$ years). ${ }^{3}$

Hyperglycemia was reported to be independently associated with worsened clinical outcomes in patients with respiratory diseases such as chronic obstructive pulmonary disease (COPD), asthma, and respiratory failure. ${ }^{4}$ Recently, the association of admission blood glucose level with the prognosis of CAP has also been evaluated. Lepper et $\mathrm{al}^{5}$ summarized evidence from several large CAP cohorts (including patients with and without COVID-19) from different geographical regions and ethnic groups, strongly suggesting that individuals with elevated blood glucose levels required special attention as they represented a group at high risk for increased mortality. However, it is still unclear whether the impact of hyperglycemia is different across various age groups. 
This study aims to compare the predictive value of blood glucose levels in elderly patients and middle-aged patients with CAP.

\section{Methods}

The study population was inpatients ( $\geq 45$ years) with a confirmed diagnosis of CAP at the Yangpu Hospital Affiliated to Tongji University from Jan. 1, 2018, to Dec. 31, 2020. The inclusion and exclusion criteria were described in Table 1.

Baseline demographics (age, gender, and smoking status), comorbidities (ischemic heart disease, malignancy, kidney disease, diabetes mellitus, cerebrovascular disease, congestive heart failure, asthma, chronic obstructive pulmonary disease, bronchiectasis, and chronic liver diseases), physical examination (altered mental status, tachycardia, respiratory rate, systolic blood pressure, and temperature), laboratory test results (blood glucose, blood urea nitrogen, hematocrit, hypoxemia, and arterial $\mathrm{pH}$ ), chest radiography findings (pleural effusion), and etiology at admission were collected from patients' medical records. Individuals should be fasting until the glucose test is being performed. The severity of illness within $24 \mathrm{~h}$ after admission was determined using the CURB-65 scoring system. ${ }^{6}$

Continuous data are presented as means \pm standard deviations (SDs) and compared using the unpaired $t$-test, categorical data are presented as numbers and percentages and compared using the chi-square test. Kaplan-Meier curves were generated for each age and blood glucose group to examine the probabilities of 28-day mortality and compared by the Log rank test. Univariate associated factors from Table 2 were offered for backward stepwise multivariable analysis with entry and exclusion limits at
0.05 and 0.10 , respectively. Multivariate Cox proportionalhazards regression was employed to calculate the hazard ratio (HR) for mortality and 95\% confidence interval (CI), after controlling for potential confounding factors. The interaction between age groups and blood glucose levels was also tested for significance. A $P$ value $<0.05$ was considered significant. The analyses were performed with the use of SPSS software v. 20.0 (IBM Corp., Armonk, NY).

\section{Results}

A total of 1656 subjects diagnosed with CAP aged $\geq 45$ years were enrolled in this study, including 592 middleaged subjects aged 45-64 years and 1064 elderly subjects aged $\geq 65$ yrs. Patients' demographics are displayed in Table 2. Most of the evaluated comorbidities (cerebrovascular disease, kidney disease, diabetes mellitus, congestive heart failure, ischemic heart disease, and chronic obstructive pulmonary disease) and several clinical presentations and laboratory test results (altered mental status, abnormal blood urea nitrogen, and abnormal hematocrit levels) were less common among middle-age patients $(P<0.01)$. The proportion of patients with an elevated blood glucose $\geq 11.1$ $\mathrm{mmol} / \mathrm{L}$ was $51.6 \%$ in those with known diabetes mellitus on admission.

The total 28-day mortality rate among all patients with CAP was $11.2 \%$, while the numbers in middle-aged and elderly subjects were $5.6 \%$ and $14.3 \%$, respectively. Figure 1 displayed the Kaplan-Meier curves categorized by blood glucose level and age. Figure 1A showed that patients with higher blood glucose levels had a lower eventfree survival rate than those with lower blood glucose levels $(\mathrm{HR}=2.36,95 \% \mathrm{CI}: 1.46-3.82 ; P<0.01)$. Figure 1B indicated

Table I Inclusion and Exclusion Criteria

\begin{tabular}{|l|l|}
\hline $\begin{array}{l}\text { Inclusion } \\
\text { criteria }\end{array}$ & $\begin{array}{l}\text { (I) Community onset; } \\
\text { (2) Presence of new infiltrate on chest X-ray or computed tomography scan together with at least one of the following: } \\
\text { (i) New or increased cough (productive, nonproductive or with a change in sputum characteristics) with or without dyspnea, } \\
\text { chest pain or hemoptysis; } \\
\text { (ii) fever; } \\
\text { (iii) Rales and/or signs of consolidation; (iv) Peripheral WBC counts }>10,000 \text { cells } / \mathrm{mm}^{3} \text { or }<4000 \text { cells } / \mathrm{mm}^{3} \text {, with or without a left } \\
\text { shift toward immature forms. }\end{array}$ \\
\hline $\begin{array}{l}\text { Exclusion } \\
\text { criteria }\end{array}$ & $\begin{array}{l}\text { (1) Acquisition of pneumonia after hospital admission or patients re-admitted after hospital discharge of }<28 \text { days; } \\
\text { (2) Presence of severe immunosuppression associated with a relevant risk of opportunistic infection, ie chemotherapy and/or } \\
\text { neutropenia of }<1000 \text { neutrophils/mL during the last } 28 \text { days, therapy with }>20 \mathrm{mg} / \text { day corticosteroids for }>14 \text { days, known HIV } \\
\text { infection and/or immunosuppressive therapy after organ or bone marrow transplant; } \\
\text { (3) Pneumonia as an expected terminal event of a severe chronic disabling comorbid condition; } \\
\text { (4) An alternative diagnosis evolving during follow-up. }\end{array}$ \\
\hline
\end{tabular}


Table 2 Demographic and Clinical Characteristics at Admission

\begin{tabular}{|c|c|c|c|c|}
\hline & Total & Middle-Age (45-59 Yrs) & Elderly ( $\geq 60$ Yrs) & $P$ value \\
\hline $\mathbf{N}$ & 1656 & 592 & 1064 & \\
\hline \multicolumn{5}{|l|}{ Demography } \\
\hline Age, yrs & $67.8 \pm 9.8$ & $54.5 \pm 9.2$ & $75.2 \pm 10.3$ & $<0.01$ \\
\hline Male, n (\%) & 927 (56.0\%) & $361(61.0 \%)$ & $566(53.2 \%)$ & $<0.01$ \\
\hline Current smoker, n (\%) & $412(24.9 \%)$ & $255(43.1 \%)$ & 157 (14.8\%) & $<0.01$ \\
\hline \multicolumn{5}{|l|}{ Comorbidities, n (\%) } \\
\hline Ischemic heart disease & $374(22.6 \%)$ & 69 (II.7\%) & $305(28.7 \%)$ & $<0.01$ \\
\hline Malignancy & $278(16.8 \%)$ & 89 (I5.0\%) & $189(17.8 \%)$ & 0.17 \\
\hline Kidney disease & 245 (14.8\%) & $61(10.3 \%)$ & I84 (I7.3\%) & $<0.01$ \\
\hline Diabetes mellitus & $215(13.0 \%)$ & 56 (9.5\%) & 159 (14.9\%) & $<0.01$ \\
\hline Cerebrovascular disease & $189(11.4 \%)$ & 31 (5.2\%) & $158(14.8 \%)$ & $<0.01$ \\
\hline Congestive heart failure & 119 (7.2\%) & 25 (4.2\%) & $94(8.8 \%)$ & $<0.01$ \\
\hline Asthma & 119 (7.2\%) & 38 (6.4\%) & 81 (7.6\%) & 0.43 \\
\hline Chronic obstructive pulmonary disease & 91 (5.5\%) & $8(1.4 \%)$ & $83(7.8 \%)$ & $<0.01$ \\
\hline Bronchiectasis & $53(3.2 \%)$ & $18(3.0 \%)$ & $35(3.3 \%)$ & 0.88 \\
\hline Chronic liver diseases & $17(1.0 \%)$ & $5(0.8 \%)$ & $12(1.1 \%)$ & 0.80 \\
\hline \multicolumn{5}{|l|}{ Physical examination, n (\%) } \\
\hline Altered mental status & $55(3.3 \%)$ & $6(1.0 \%)$ & $49(4.6 \%)$ & $<0.01$ \\
\hline Tachycardia (pulse rate $\geq 125 / \mathrm{min}$ ) & $188(11.4 \%)$ & 75 (I2.7\%) & $113(10.6 \%)$ & 0.23 \\
\hline Respiratory rate $\geq 30 / \mathrm{min}$ & $45(2.7 \%)$ & $10(1.7 \%)$ & $35(3.3 \%)$ & 0.06 \\
\hline Systolic blood pressure $<90 \mathrm{mmHg}$ & 78 (4.7\%) & $24(4.1 \%)$ & $54(5.1 \%)$ & 0.40 \\
\hline Temperature $<35^{\circ} \mathrm{C}$ or $\geq 40^{\circ} \mathrm{C}$ & 81 (4.9\%) & $28(4.7 \%)$ & $53(5.0 \%)$ & 0.91 \\
\hline \multicolumn{5}{|l|}{ Laboratory and radiologic measures, n (\%) } \\
\hline Blood glucose $\geq 11.1 \mathrm{mmol} / \mathrm{L}$ & $172(10.4 \%)$ & $58(9.8 \%)$ & $114(10.7 \%)$ & 0.61 \\
\hline Blood urea nitrogen $\geq 7 \mathrm{mmol} / \mathrm{L}$ & $340(20.5 \%)$ & $77(13.0 \%)$ & $263(24.7 \%)$ & $<0.01$ \\
\hline Hematocrit $<30 \%$ & $294(17.8 \%)$ & 79 (I3.3\%) & $215(20.2 \%)$ & $<0.01$ \\
\hline Hypoxemia $(\mathrm{PaO} 2<60 \mathrm{mmHg}$ or $\mathrm{SaO} 2<90 \%)$ & $180(10.9 \%)$ & $61(10.3 \%)$ & $119(11.2 \%)$ & 0.62 \\
\hline Arterial $\mathrm{pH}<7.35$ & $102(6.2 \%)$ & 35 (5.9\%) & $67(6.3 \%)$ & 0.26 \\
\hline Pleural effusion & $563(34.0 \%)$ & $209(35.3 \%)$ & $354(33.3 \%)$ & 0.65 \\
\hline \multicolumn{5}{|l|}{ Etiology } \\
\hline Mycoplasma pneumonia & $127(7.7 \%)$ & $68(11.5 \%)$ & 59 (5.5\%) & $<0.01$ \\
\hline Streptococcus pneumonia & $105(6.3 \%)$ & $38(6.4 \%)$ & $67(6.3 \%)$ & 0.92 \\
\hline Haemophilus influenzae & 87 (5.3\%) & $30(5.1 \%)$ & 57 (5.4\%) & 0.91 \\
\hline Chlamydia pneumoniae & 72 (4.3\%) & 25 (4.2\%) & 47 (4.4\%) & 0.90 \\
\hline Klebsiella pneumoniae & $27(1.6 \%)$ & $8(1.7 \%)$ & 17 (1.6\%) & 0.83 \\
\hline Staphylococcus aureus & $20(1.2 \%)$ & $6(1.0 \%)$ & $14(1.3 \%)$ & 0.65 \\
\hline Legionella pneumophila & $14(0.8 \%)$ & $6(1.0 \%)$ & $8(0.8 \%)$ & 0.58 \\
\hline Escherichia coli & $15(0.9 \%)$ & $6(1.0 \%)$ & $9(0.9 \%)$ & 0.79 \\
\hline \multicolumn{5}{|l|}{ CURB-65 } \\
\hline $0-1$ & $500(30.2 \%)$ & $415(70.1 \%)$ & 85 (8.0\%) & $<0.01$ \\
\hline 2 & $683(41.2 \%)$ & 139 (23.5\%) & $544(51.1 \%)$ & \\
\hline $3-5$ & $473(28.6 \%)$ & $38(6.4 \%)$ & 435 (40.9\%) & \\
\hline ICU admission & $120(7.2 \%)$ & 35 (5.9\%) & $85(8.0 \%)$ & 0.14 \\
\hline Length of stay (days) & $13.09 \pm 9.9$ & $12.7 \pm 9.6$ & $13.3 \pm 10.3$ & 0.71 \\
\hline
\end{tabular}


A

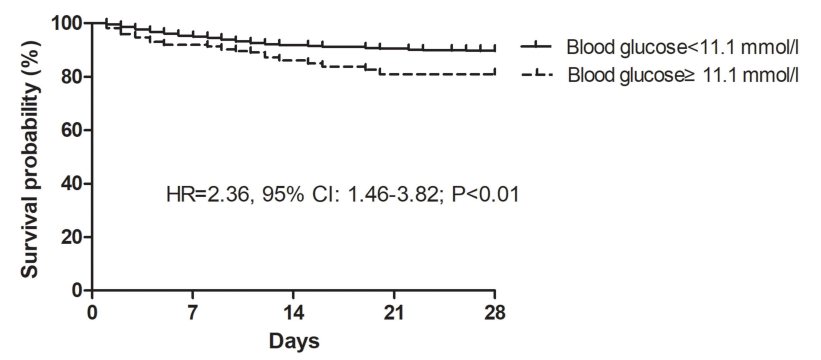

C

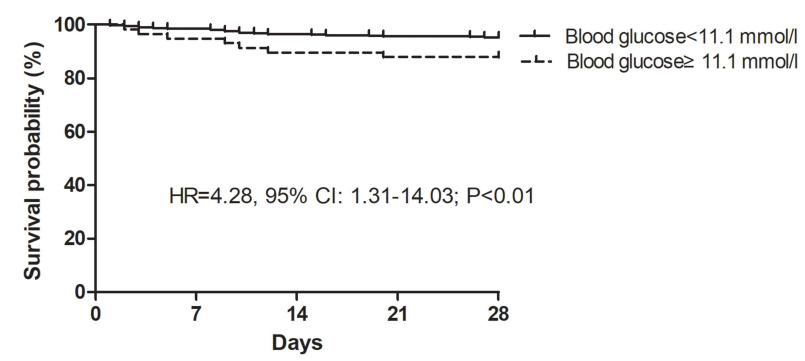

B

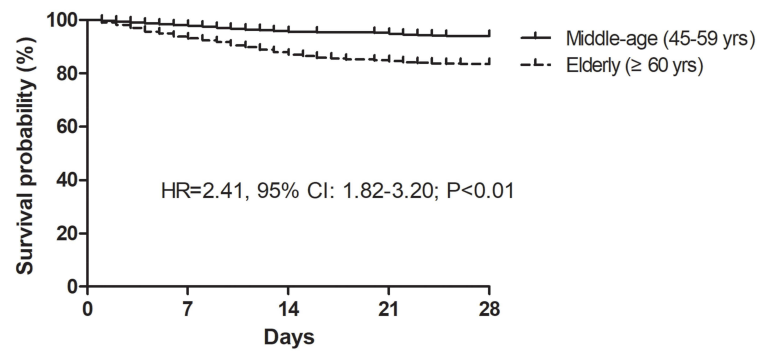

\section{D}

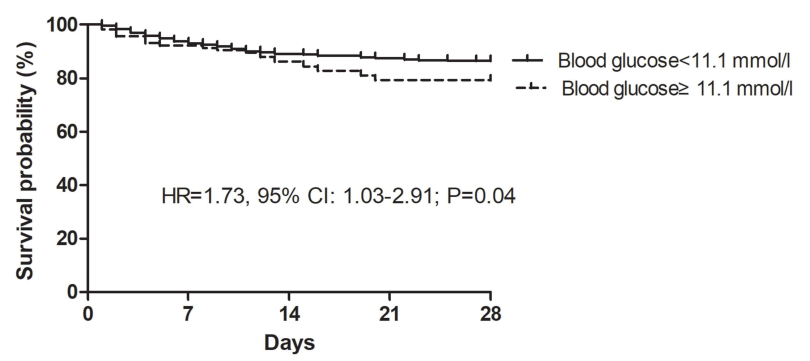

Figure I Kaplan-Meier survival curves for inpatients with community acquired pneumonia (CAP) according to blood glucose level (A), age (B), blood glucose level in middle-age subjects $45-64$ years (C), and blood glucose level in elderly $\geq 65$ years (D).

that elderly patients had a lower chance of survival $(\mathrm{HR}=2.41,95 \% \mathrm{CI}: 1.82-3.20 ; P<0.01)$. Higher blood glucose levels were associated with worse event-free survival in both middle-aged (Figure 1C, $\mathrm{HR}=4.28$, 95\% CI: $1.31-$ 14.03; $P<0.01$ ) and elderly (Figure $1 \mathrm{D}, \mathrm{HR}=1.73,95 \% \mathrm{CI}$ : 1.03-2.91; $P=0.04$ ) patients.

Univariate analyses (Table 3 ) indicated that age, gender, malignancy, kidney disease, diabetes mellitus, congestive heart failure, asthma, altered mental status, tachycardia, respiratory rate, systolic blood pressure, blood urea nitrogen, hypoxemia, arterial $\mathrm{pH}$, pleural effusion, CURB-65, and ICU admission were significantly associated with the 28day mortality (all $P<0.05$ ). Multivariate Cox proportionalhazards regression analyses showed that both blood glucose level $(\mathrm{HR}=2.08,95 \% \mathrm{CI}: 1.38-3.49 ; P<0.01)$ and age $(\mathrm{HR}=2.76,95 \% \mathrm{CI}: 1.65-3.77 ; P<0.01)$ were significantly associated with a higher risk of mortality in all patients, after controlling for potential confounder factors including gender, malignancy, kidney disease, diabetes mellitus, congestive heart failure, asthma, altered mental status, tachycardia, respiratory rate, systolic blood pressure, blood urea nitrogen, hypoxemia, arterial pH, pleural effusion, CURB-65, and ICU admission (Table 4). In the stratified analysis, the association of blood glucose level and mortality was demonstrated to be statistically significant in both middle-age $(\mathrm{HR}=4.48$, 95\% CI: $1.40-13.65 ; P<0.01)$ and elderly patients $(\mathrm{HR}=1.52,95 \% \mathrm{CI}: 1.09-2.17 ; P=0.05)$; however, the effect of blood glucose appeared to be more pronounced among middle-aged patients than among elderly patients ( $P=0.01$ for the interaction).

\section{Discussion}

Our research outcomes confirm the positive association of admission blood glucose and mortality in subjects with CAP. Moreover, the strength of the association decreased with age ( $P=0.01$ for the interaction) as the adjusted hazard ratios for 28-day mortality were 4.48 (95\% CI: $1.40-13.65)$ in patients aged 45-64 years and $1.52(95 \%$ CI: 1.09-2.17) in patients aged above $\geq 65$ years.

People with an increased blood glucose level face a greater risk of infections. ${ }^{7}$ However, the biological mechanism was not elaborated. It is argued that a hyperglycemic environment may impair the function of neutrophils and monocytes and increase susceptibility to certain organisms. ${ }^{8,9}$ A Danish retrospective study involving 1318 adult CAP patients reported that in subjects without diabetes metabolism, a higher blood glucose level was an independent predictor for intensive care unit (ICU) admission $(\mathrm{OR}=1.25$, 95\% CI 1.13-1.39). ${ }^{10}$ Multivariate logistic regression analysis in a Chinese retrospective study showed that a higher admission blood glucose level was significantly associated with the 30-day all-cause mortality $(\mathrm{OR}=1.91,95 \% \mathrm{CI}$ : 
Table 3 Univariate Analysis of Risk Factors for 28-Day Mortality in Patients with Community-Acquired Pneumonia (CAP)

\begin{tabular}{|c|c|c|c|}
\hline & OR & $95 \% \mathrm{Cl}$ & $P$ value \\
\hline \multicolumn{4}{|l|}{ Demography } \\
\hline$\geq 60$ yrs vs $45-59$ yrs & 2.41 & $1.82-3.20$ & $<0.01$ \\
\hline Male vs Female & 1.68 & $1.09-2.27$ & 0.02 \\
\hline Current smoker vs Non-smoker & 1.45 & $0.87-1.95$ & 0.18 \\
\hline \multicolumn{4}{|l|}{ Comorbidities } \\
\hline Ischemic heart disease & 1.42 & $0.75-1.98$ & 0.13 \\
\hline Malignancy & 2.13 & $1.37-3.10$ & $<0.01$ \\
\hline Kidney disease & 1.65 & I.17-2.37 & 0.01 \\
\hline Diabetes mellitus & 2.09 & $1.43-2.88$ & $<0.01$ \\
\hline Cerebrovascular disease & 1.66 & $0.92-2.51$ & 0.19 \\
\hline Congestive heart failure & 2.25 & $1.67-3.29$ & $<0.01$ \\
\hline Asthma & 1.47 & $0.97-1.89$ & 0.09 \\
\hline Chronic obstructive pulmonary disease & 1.31 & $0.77-2.01$ & 0.45 \\
\hline Bronchiectasis & 1.25 & $0.65-1.87$ & 0.53 \\
\hline Chronic liver diseases & 1.64 & $0.89-2.33$ & 0.18 \\
\hline \multicolumn{4}{|l|}{ Physical examination } \\
\hline Altered mental status & 1.72 & I.32-2.43 & $<0.01$ \\
\hline Tachycardia (pulse rate $\geq 125 / \mathrm{min}$ ) & 1.88 & $1.4 \mathrm{I}-2.75$ & $<0.01$ \\
\hline Respiratory rate $\geq 30 / \mathrm{min}$ & 1.59 & $\mathrm{I} .10-2.03$ & 0.01 \\
\hline Systolic blood pressure $<90 \mathrm{mmHg}$ & 1.82 & $1.35-2.43$ & $<0.01$ \\
\hline Temperature $<35^{\circ} \mathrm{C}$ or $\geq 40^{\circ} \mathrm{C}$ & 1.16 & $0.57-1.64$ & 0.82 \\
\hline \multicolumn{4}{|l|}{ Laboratory and radiologic measures } \\
\hline Blood glucose $\geq 11.1 \mathrm{mmol} / \mathrm{L}$ & 2.36 & $1.46-3.82$ & $<0.01$ \\
\hline Blood urea nitrogen $\geq 7 \mathrm{mmol} / \mathrm{L}$ & 2.03 & $1.28-3.26$ & $<0.01$ \\
\hline Hematocrit $<30 \%$ & 1.65 & $0.76-2.32$ & 0.43 \\
\hline Hypoxemia $(\mathrm{PaO} 2<60 \mathrm{mmHg}$ or $\mathrm{SaO} 2<90 \%)$ & 1.56 & $1.17-2.19$ & 0.02 \\
\hline Arterial $\mathrm{pH}<7.35$ & 1.89 & $1.34-2.77$ & $<0.01$ \\
\hline Pleural effusion & 2.15 & $1.76-3.17$ & $<0.01$ \\
\hline \multicolumn{4}{|l|}{ Etiology } \\
\hline Mycoplasma pneumonia & 1.06 & $0.53-1.85$ & 0.65 \\
\hline Streptococcus pneumonia & 0.86 & $0.48-1.76$ & 0.73 \\
\hline Haemophilus influenzae & 1.35 & $0.65-1.98$ & 0.87 \\
\hline Chlamydia pneumoniae & 0.91 & $0.76-1.18$ & 0.49 \\
\hline Klebsiella pneumoniae & 1.19 & $0.3 I-2.05$ & 0.82 \\
\hline Staphylococcus aureus & 0.65 & $0.39-1.18$ & 0.32 \\
\hline Legionella pneumophila & 0.88 & $0.65-1.08$ & 0.20 \\
\hline Escherichia coli & 0.92 & $0.7 I-I .32$ & 0.90 \\
\hline \multicolumn{4}{|l|}{ CURB-65 } \\
\hline $0-1$ & Ref. & & \\
\hline 2 & 1.86 & $1.32-2.75$ & $<0.01$ \\
\hline $3-5$ & 2.36 & $1.80-3.13$ & $<0.01$ \\
\hline ICU admission & 2.71 & $1.99-3.86$ & $<0.01$ \\
\hline Length of stay & 1.32 & $0.81-1.76$ & 0.25 \\
\hline
\end{tabular}

1.746-2.082; $P<0.001)$ and cardiac mortality $(\mathrm{OR}=1.97$, 95\% CI: $1.774-2.191 ; P<0.001)$ after adjusting for potential confounding factors. ${ }^{11}$ Consistent with previous studies, our results confirmed that an elevated admission blood glucose level was significantly associated with a higher risk of allcause mortality in patients with CAP. 
Table 4 Multivariate Analysis for Evaluating the Association of Blood Glucose Level and Age with 28-Day Mortality in Patients with Community Acquired Pneumonia (CAP)

\begin{tabular}{|c|c|c|c|}
\hline & \multicolumn{3}{|c|}{ Multivariate Analysis* } \\
\hline & $\begin{array}{l}\text { Hazard } \\
\text { Ratio }\end{array}$ & $95 \% \mathrm{Cl}$ & $P$ value \\
\hline All population & & & \\
\hline $\begin{array}{l}\text { Blood glucose level } \geq \text { vs } \\
<\text { II.I mmol/l }\end{array}$ & 2.08 & I.38-3.49 & $<0.01$ \\
\hline Age $\geq$ vs $<60$ yrs & 2.76 & $1.65-3.77$ & $<0.01$ \\
\hline $\begin{array}{l}\text { Middle-age }(45-59 \mathrm{yrs}) \\
\text { Blood glucose level } \geq \text { vs } \\
<11.1 \mathrm{mmol} / \mathrm{l}\end{array}$ & 4.48 & $1.40-13.65$ & $<0.01$ \\
\hline Elderly ( $\geq 60$ yrs) & & & \\
\hline $\begin{array}{l}\text { Blood glucose level } \geq \text { vs } \\
<11.1 \mathrm{mmol} / \mathrm{l}\end{array}$ & 1.52 & $1.09-2.17$ & 0.05 \\
\hline
\end{tabular}

Notes: *Hazard ratios with $95 \% \mathrm{Cls}$ were calculated using the multivariate Cox proportional-hazards regression, after adjustment for gender, malignancy, kidney disease, diabetes mellitus, congestive heart failure, asthma, altered mental status, tachycardia, respiratory rate, systolic blood pressure, blood urea nitrogen, hypoxemia, arterial pH, pleural effusion, CURB-65, and ICU admission.

The most important finding of this study is that the association between CAP and short-term mortality was stronger at younger ages. A Mexico study involving 757,210 patients with COVID-19 indicated that the risk of death associated with diabetes decreased with age. The hazard ratio for death was 3.12 (95\% CI: 2.86-3.40) for patients aged 20-39 years, 2.33 (95\% CI: $2.22-2.44$ ) for patients aged $40-49$ years, 1.74 (95\% CI: 1.68-1.79) for patients aged 50-59 years, 1.41 (95\% CI: $1.37-1.45$ ) for patients aged 60-69 years, 1.20 (95\% CI: 1.17-1.24) for patients aged 70-79 years, and 1.11 (95\% CI: 1.06-1.16) for patients aged 80 years or older (trend test: $P=0.004){ }^{12}$ Their outcomes were similar to our findings. However, the mechanism behind the weaker association of blood glucose and CAP-related mortality in older subjects was not clear. Several pre-existing comorbidities were less likely to be identified or reported in the older population, which may attenuate the association of blood glucose with mortality in these patients. In addition, ageing is associated with a progressively weakened immune system and decreased lung performance. In line with previous studies, ${ }^{13,14}$ our results indicate that age is one of the strongest independent predictors of mortality in patients with pneumonia. Thus, it is assumed that elevated blood glucose may not further increase the risk of death in older patients as they are already at very high risk.

There are some limitations in the present study. As a retrospective study, it is not possible to conclude any causal inference between blood glucose and clinical outcome as some residual confounding may not be captured. In addition, the variations in serum glucose during the hospitalization were not measured. The potential risk of mortality caused by hyperglycemia might be underestimated as patients with a higher blood glucose level may have received antihyperglycemic treatments.

\section{Conclusions}

In conclusion, our study indicated that an increased blood glucose level at admission was significantly associated with an elevated risk of 28-day mortality in patients with CAP, and the association was stronger at younger ages.

\section{Data Sharing Statement}

All data accessed complied with relevant data protection and privacy regulations. Data are available on reasonable request from the corresponding authors.

\section{Ethics Approval and Informed Consent}

All procedures were conducted according to the ethical standards of the Institutional Review Board of Yangpu Hospital Affiliated to Tongji University and the 1964 Declaration of Helsinki and its later amendments or comparable ethical standards. Informed consents were waived by Institutional Review Board of Yangpu Hospital Affiliated to Tongji University as it is a retrospective observational study.

\section{Disclosure}

The authors declare that there is no conflict of interest.

\section{References}

1. Shoar S, Musher DM. Etiology of community-acquired pneumonia in adults: a systematic review. Pneumonia. 2020;12:11. PubMed PMID: 33024653; PubMed Central PMCID: PMCPMC7533148. doi:10.1186/ s41479-020-00074-3

2. McLaughlin JM, Khan FL, Thoburn EA, et al. Rates of hospitalization for community-acquired pneumonia among US adults: a systematic review. Vaccine. 2020;38(4):741-751. PubMed PMID: 31843272. doi:10.1016/j.vaccine.2019.10.101

3. Sun Y, Li H, Pei Z, et al. Incidence of community-acquired pneumonia in urban China: a national population-based study. Vaccine. 2020;38 (52):8362-8370. PubMed PMID: 33199077. doi:10.1016/j.vaccine.20 20.11.004

4. Liu SP, Zhang Q, Wang W, et al. Hyperglycemia is a strong predictor of poor prognosis in COVID-19. Diabetes Res Clin Pract. 2020;167:108338. PubMed PMID: 32712122; PubMed Central PMCID: PMCPMC7377976. doi:10.1016/j.diabres.2020.108338 
5. Lepper PM, Bals R, Juni P, et al. Blood glucose, diabetes and metabolic control in patients with community-acquired pneumonia. Diabetologia. 2020;63(11):2488-2490. PubMed PMID: 32676817; PubMed Central PMCID: PMCPMC7366469. doi:10.1007/s00125020-05225-1

6. Lim WS, van der Eerden MM, Laing R, et al. Defining community acquired pneumonia severity on presentation to hospital: an international derivation and validation study. Thorax. 2003;58 (5):377-382. PubMed PMID: 12728155; PubMed Central PMCID PMCPMC1746657. doi:10.1136/thorax.58.5.377

7. Abu-Ashour W, Twells L, Valcour J, et al. The association between diabetes mellitus and incident infections: a systematic review and meta-analysis of observational studies. BMJ Open Diabetes Res Care. 2017;5(1):e000336. PubMed PMID: 28761647; PubMed Central PMCID: PMCPMC5530269. doi:10.1136/bmjdrc-2016000336

8. Insuela DBR, Ferrero MR, Goncalves-de-Albuquerque CF, et al. Glucagon reduces neutrophil migration and increases susceptibility to sepsis in diabetic mice. Front Immunol. 2021;12:633540. PubMed PMID: 34295325; PubMed Central PMCID: PMCPMC8290340. doi:10.3389/fimmu.2021.633540

9. Johnson J, Jaggers RM, Sreejit G, et al. Oxidative stress in neutrophils: implications for diabetic cardiovascular complications. Antioxid Redox Signal. 2021. PubMed PMID: 34148367. doi:10.10 89/ars.2021.0116
10. Jensen AV, Egelund GB, Andersen SB, et al. The impact of blood glucose on community-acquired pneumonia: a retrospective cohort study. ERJ Open Res. 2017;3(2):00114-2016. PubMed PMID: 28656133; PubMed Central PMCID: PMCPMC5478863. doi: $10.1183 / 23120541.00114-2016$

11. Ma J, He L, Wang X, et al. Relationship between admission blood glucose level and prognosis in elderly patients without previously known diabetes who undergo emergency non-cardiac surgery. Intern Emerg Med. 2015;10(5):561-566. PubMed PMID: 25616429. doi:10.1007/s11739-015-1191-y

12. Woolcott OO, Castilla-Bancayan JP. The effect of age on the association between diabetes and mortality in adult patients with COVID-19 in Mexico. Sci Rep. 2021;11(1):8386. PubMed PMID: 33863997; PubMed Central PMCID: PMCPMC8052362. doi:10.1038/s41598-021-88014-z

13. Ruiz LA, Espana PP, Gomez A, et al. Age-related differences in management and outcomes in hospitalized healthy and well-functioning bacteremic pneumococcal pneumonia patients: a cohort study. BMC Geriatr. 2017;17(1):130. PubMed PMID: 28633626; PubMed Central PMCID: PMCPMC5477680. doi:10.1186/s12877-017-0518-0

14. Han X, Zhou F, Li H, et al. Effects of age, comorbidity and adherence to current antimicrobial guidelines on mortality in hospitalized elderly patients with community-acquired pneumonia. BMC Infect Dis. 2018;18(1):192. PubMed PMID: 29699493; PubMed Central PMCID: PMCPMC5922029. doi:10.1186/s12879-018-3098-5
International Journal of General Medicine

\section{Publish your work in this journal}

The International Journal of General Medicine is an international, peer-reviewed open-access journal that focuses on general and internal medicine, pathogenesis, epidemiology, diagnosis, monitoring and treatment protocols. The journal is characterized by the rapid reporting of reviews, original research and clinical studies across all disease areas. The manuscript management system is completely online and includes a very quick and fair peer-review system, which is all easy to use. Visit http://www.dovepress.com/ testimonials.php to read real quotes from published authors. 